\title{
Órbitas estéticas: visualidades, corpos e cotidianos
}

Aldo Victorio Filho

\section{Resumo}

Este texto pretende discorrer sobre alguns assuntos que referenciam as pesquisas que oriento e que são caros aos meus interesses investigativos: o corpo, a imagem visual, a diferença e suas estéticas negadas, os cotidianos escolares e urbanos e suas práticas poéticas. Assuntos-universos que tomo como fontes de saberes indispensáveis à atualização das práticas escolares e da ampliação alargada das práticas poéticas. Para tanto, em benefício do seu aproveitamento no diálogo com outras pesquisas, e pesquisadores de alguma forma interessados nesses temas abertos, busco neste artigo explicitar e discutir alguns dos sentidos que Ihes possam ser atribuídos.

\section{Palavras chave}

corpo, cidade, imagem visual, periferizações

\section{Aesthetic orbits: visualities, bodies and everyday life}

\begin{abstract}
The proposal seeks to approach some subjects that are currently under my supervised research interests: the body, the visual image, the difference and their denied aesthetics and, finally, the everyday urban school and its poetic practices. I've sought subjectuniverses that I take as sources of knowledge indispensable to upgrade school practices and expand the poetic ones. By this way I try to achieve the benefit of their use in research and dialogue with others researchers, linked, in some way, in these open issues. So, in this article I seek to explain and discuss some of the meanings that can be attributed to these subject-universes.
\end{abstract}

\section{Keywords}

body, city, visual image, periphery

\section{Uma introdução: a linha de pesquisa}

As pesquisas desenvolvidas na Linha de pesquisa 'Arte, subjetividade, política e formação humana', do Programa de pós-graduação em Artes do Instituto de Artes da UERJ, têm como um dos nortes a Arte em dimensão ampliada e irredutível a um dos sentidos que sua polissemia oferece. Entendemos a Arte, nessa linha específica de investigação, como uma notável fonte de ligação entre as esferas do mundo social, com suas conhecidas estruturas de governo no campo da vida privada, do espaço público e/ou político, do 
cotidiano, das esferas do poder, da religião e das instituições, o campo da arte como produção estética destinada aos coletivos e que sempre se notabilizou como espaço de formação humana.

Pelo menos desde a era clássica acompanhamos os modos como são apropriados e apreendidos, num dado conjunto de textos e de obras, os valores estéticos e/ou éticos agregados à arte que passam a servir. Inclusive. àquilo que compreende $o$ fazer e 0 pensar arte. Não obstante, o fascínio que o século XX, e mais recentemente o século XXI, experimentam com os novos dispositivos e tecnologias, que não raro problematizam este topos "arte como formação humana", expõem novas fissuras nos espaços da crítica e da teoria da arte, dentre elas a incompatibilidade entre a idéia de valor e o relativismo cultural que se, por um lado contribui para certo ocaso da tradição clássica, por outro, aventam novos modos de se pensar e de se fazer arte no vetor formação humana a partir de práticas performativas e de ações poéticas que percorrem estes lugares: arte \& política, arte \& ciência, arte \& sociedade.

Outro desdobramento possível deste cenário corresponde à aproximação entre a ética e a estética que emergem como campos afirmativos destes novos contextos da criação, produção, difusão e recepção da arte e da cultura no mundo contemporâneo. Assim, a linha de pesquisa solicita uma interlocução vital, não somente com a filosofia mas empreende junto a esta o redimensionamento dos estudos do corpo e das artes performativas a saber: o teatro, a dança e a performance, com o objetivo de propor um novo enunciado, uma nova episteme. Acreditar que mesmo sob o signo das mutações genéticas, do corpo cyborgue, dos processos de transgenização da vida vigentes no mundo atual, a recuperação deste enunciado "arte como formação humana" significa radicalizar o lugar da autopoiesis ${ }^{1}$ como afirmação do humano e da vida em toda sua dimensão infinita e mutável. Após a breve introdução que pretende afirmar as intenções dos investimentos investigativos da linha de pesquisa que abriga as pesquisas sob a minha orientação, esse artigo se atém ao que orbita as referidas pesquisas. Pesquisas cujos espaços alcançam os territórios escolares, as ruas, bairros e ocupações poéticas diversas. Pesquisas que se ocupam das imagens de adolescentes aos corpos performáticos em radicais investidas poéticas e que guardam aproximações maiores e mais densas que o mero fato de serem desenvolvidas no mesmo programa ou linha de pesquisa.

\footnotetext{
${ }^{1}$ Autopoiese ou autopoiesis (do grego auto "próprio", poiesis "criação") é um termo cunhado na década de 1970 pelos biólogos e filósofos chilenos Francisco Varela e Humberto Maturana para designar a capacidade dos seres vivos de produzirem a si próprios. Segundo esta teoria, um ser vivo é um sistema autopoiético, caracterizado como uma rede fechada de produções moleculares (processos) em que as moléculas produzidas geram com suas interações a mesma rede de moléculas que as produziu. A conservação da autopoiese e Revisaa daptação de um ser vivo ao seu meio são condições sistêmicas para a vida. 
As juventudes, os corpos, a cultura Visual, a cidade, etc., surgem como conexões de uma rede de afetos e afetações, que tomam os encontros humanos, seja nas afinidades diante determinadas experiências estéticas, seja na fugacidade de algum abrigo identitário ou na eloquência fugaz do ato performático, que evidenciam a densidade e intensidade do amálgama entre a criação poética e a formação humana. As energias políticas contidas na feitura cotidiana da vida como realização estética não seriam, em nossa perspectiva, distantes das energias políticas implícitas no ato objetivamente poético ou objetivamente pedagógico. Assim, as criações e experiências, artísticas ou não, eleitas pelas pesquisas apontam fontes epistêmicas de grande utilidade para a compreensão e aproveitamento dos tempos e acontecimentos atuais nos espaços diversos de atuação poética, hospital, galerias, escolas, ruas ou barbearias, entre tantos outros espaços de acontecimento das obras, dos encontros e da formação humana.

Instituições tradicionalmente fixadas em determinadas finalidades e, consequentemente, compreendidas na limitação de suas narrativas foram, e ainda são, permanentemente atravessadas pelas experiências trazidas pelos praticantes de seus cotidianos (CERTEAU, 1994, p.103), o que multiplicaria cada instituição na medida em que as diferentes combinações de experiências, sem eclipsar os sentidos e finalidades institucionais, conferem singularidades às escolas, hospitais, academias, etc. Dentre as pesquisas de que nos ocupamos, algumas são realizadas em escolas públicas populares, uma delas em um hospital público, outras no ilimitado espaço poético que tem a cidade, tanto nos ambientes particulares de ateliers e galerias, quanto nas próprias ruas e praças da cidade mundo.

A aparente agudeza da diversidade de espaços institucionais, privados e públicos não afasta a afinidade dos elementos norteadores das pesquisas que os tem como campo. Se o corpo na experiência hospitalar se movimenta em ritmo singular entre a quietude terapêutica e a espontaneidade dos espasmos, não se distancia, entretanto, da aparente obediência do corpo do estudante que, por sua vez, se aquieta na dolência das imposições disciplinares e, em intervalos imprevisíveis, fulgura na efervescência corpórea juvenil.

\section{O corpo que tudo orbita e que é a órbita de tudo}

O que é um corpo? É uma respiração que fala (JOSÉ GIL). Ignorado ou evitado e até marginalizado, o corpo esteve ausente da maior parte das produções teóricas filosóficas, culturais ou políticas. Nestes textos, a ação humana, e o que poderia ser considerado a identidade das pessoas, eram reduzidas ao idealizado 
território da mente. Dicotomia de preço alto entre o pensamento, a imaginação ou as criações mentais e o corpo, instrumento auxiliar cujas incalculáveis potências sensoriais, se situavam ao que a palavra e o sentido instituído poderiam alcançar. Alcance cerceado não apenas pela limitação quantitativa do vocabulário como também, e principalmente, pelo que habita os subterrâneos da palavra proferida. Das exclusões às afirmações políticas de toda sorte de interesse, do gênero às demais verdades impostas. A mente ou alma foi imposta como fonte da verdade sobre tudo, em sua justa racionalidade se impõe fonte limite do conhecimento, de forma a abrandar a problemática da decorrente relação entre o corpo e a mente dicotomizados. Entretanto, na história da filosofia, alguns pensadores como Hume, por exemplo, têm em suas obras considerações que sugerem reflexão alargada sobre a significação do corpo, quando afirma que a experiência do mundo depende inteiramente dos órgãos dos sentidos. Embora, o potencial perceptivo do corpo tenha sido eclipsado pela ênfase dada à visão e à audição, como meios mais significativos, e até decisivos de conhecimento.

Os sentidos corporais mais óbvios, como tato, olfato e paladar foram postos de lado e fatalmente ignoradas as implicações que esses sentidos têm nos envolvimentos práticos dos sujeitos com seus mundos e demais consequentes inteirações. Sem pretender aprofundar as considerações sobre o corpo no campo da Filosofia, convém observar que ainda no século XVIII Kant manifestou o status problemático dos sentidos em sua Crítica da razão. Embora, tenha argumentado que apenas as criaturas racionais e sensuais ou incorporadas seriam as que poderiam experimentar o prazer da beleza, tomado como oposto ao prazer puramente racional, na qualidade agradável, moralmente boa ou puramente física, da comida e da bebida. Assim, entende que a beleza estaria na visão e na audição, descartando a relação estética realizada pelos demais sentidos.

Saltando à contemporaneidade, temos o corpo reinventado para além dos limites que o diagramaram em oposição e subserviência à razão ou à mente. A reinvenção do corpo aqui apontado é observada nos desdobramentos dos movimentos emancipatórios que emergiram no século XX e se intensificaram na atualidade.

Em sintonia com o estilhaçamento do gênero e demais clausuras identitárias, o corpo é afirmado em muitas ampliações em termos de pluralidade, alargamento e profundidade, de presença e sentidos. Plataforma e energia que desintegram os regimes de certezas que o continham em sentidos despretensiosos. O corpo é o que pensa, é o que subverte a linguagem e escapa de suas contenções; por meio da linguagem se dão as verdades os limites dos sentidos e o controle de suas transgressões, e de suas armadilhas - só se enuncia o que o vocabulário autoriza, ao corrompê-lo dentro de seu sistema ainda se 
estaria sob o domínio estratégico da linguagem - é, contudo, na visceralidade da linguagem que o corpo expandido como ação poética cria territórios e movimentos cujo ineditismo se assenta na pulverização do sentido pela potência da presença. O corpo irremediavelmente divorciado do sentido, ou seja, de ciladas hermenêuticas que arrisquem reduzi-lo às anacrônicas celas categoriais, configura um instigante horizonte de possibilidades poéticas assim como implica em reconsiderar as condições pretéritas que o eclipsaram em nome da razão e do sentido desencarnados.

Aceitada a ideia de que o corpo afirmado na atualidade não é outro amputado do que fora outrora, assim, o corpo passado, já liberto dos disfarces, aparências e mimetismos de licitude, é ativado sob as ações e possibilidades atuais. Tal performance presentificadora alude à fisicalidade e experiência informe do corpo (SILVA, 2013) que atravessa e ultrapassa camadas de experiências, de sentidos, de contenções e reduções e, assim, gera complexidades e zonas desestabilizantes.

Onde residiria a importância desses atravessamentos, dessas atualizações e ofertas do corpo? Estaria aqui a importância de sua referência, na oferta de saberes via percepção radical e a poemação dos sentidos ativados na experiência poética da carne-viva. Ou na possibilidade do mergulho incerto através das intensidades do processo de busca de uma criação performativa pulsante (idem), comprometida com a presença do corpo e de sua atuação mesclada na horizontalidade da intuição, da sensorialidade e da articulação de sentidos.

A aludida transversalidade aponta, por sua vez, para uma perspectiva nova. Para um panorama de sentidos resultante do jogo entre linguagens artísticas, entre modos de ser e vibrar o corpo que evidenciam a tensão entre as suas potências. Energias consideradas para além dos aspectos visuais, racionais ou interpretativos pelo limite da palavra. 0 corpo ampliado pela diluição do poder do sentido se empodera pela presença e oferece as rasuras, os desvios, caminhos, trilhas e desvios de investigação errática como nomadismos preciosos à arte e demais aventuras intelectuais dos tempos de agora.

São, portanto, as provocações do corpo, tentativas de sua descolonização pelos dispositivos da linguagem na invenção de mitologias, arqueologias pessoais e coletivas, rastros e indícios diversos do corpo nos cotidianos e coletivos das cidades, imagens visuais, diários, fotos, cartas, pequenas e grandiosas afirmações das subjetividades e de suas redes. Mais que as articulações discursivas, figurinos, peles orgânicas e simbólicas, carapaças afetivas ou protéticas, os fluidos, as tintas, as presenças irrefutáveis do corpo são a trama constituidora do corpo interessado. A concretude das experiências, das 
esperas preenchidas de vazio, dos textos jamais escritos ou pronunciados, também explicita a presença do corpo em sua inexorável existência.

A experiência corporal oferece ao incorporado na ação ou ao corpo que o encontra os processos de grafias, de poiesis desviantes e que interessam às abordagens praticadas no âmbito de nossas investigações. Seja na formalidade ou no automatismo performático da escrita, escrita para além do que Ihe fora determinado, escrita objeto, ação, escrita arquitetura, perambulação, escrita poética, escrita corpo.

\section{A imagem visual}

Imaginação é a capacidade de fazer e decifrar imagens (FLUSSER)

O termo imagem por mais discutido, examinado e problematizado sob diferentes perspectivas ao longo das últimas décadas continua sendo fonte de interrogações e universo de investimentos explicativos e de novas narrativas. O que certamente é afirmável, sem grandes riscos de incorrer em erro, é que a imagem, assim como o corpo, pode não ser redutível à palavra. Sobretudo, a imagem visual que se vale, inexoravelmente, do seu corpo material, a um só termo, forma e conteúdo, a despeito das narrativas que gera ou venha a gerar. Sabemos que a imagem visual vem conquistando espaços cada vez mais significativos na atenção de grande parte da humanidade e, curiosamente simultâneo à resistência e recusa do corpo de ser reduzido aos sentidos da visão e da audição, a produção, circulação, intensidade e eloquência das imagens visuais superam a participação das paisagens sonoras nos diferentes cotidianos.

Evidentemente que a produção musical e o acontecimento sonoro parecem monopolizar, juntamente com as imagens visuais, a percepção da maioria das pessoas alcançadas pela citadinização do mundo. Em outros termos, o alcance das sensações e demais implicações da cidade imaginária que a comunicação midiática e, nesta, a publicidade procura impor a todos, situa a crença de pertencimento a um território homogeneizadamente urbano no qual determinados compromissos de comportamento e consumo são naturalizados.

Pensar a produção e circulação das imagens visuais implica, portanto, em buscar considerar o panorama das narrativas visuais, suas contradições e participação no cotidiano da aventada cidade-mundo de postulação sub-reptícia nos canais de comunicação contemporâneos. As imposição dos designs dos dispositivos de comunicação levam sujeitos de culturas distanciadas por complexidades intrínsecas a comungarem os mesmos conhecimentos operacionais diante das telas e nas paisagens virtuais. Provavelmente tal partilha de saberes não se reduz às operações de programas 
de computadores ou de telefonia móvel. Como qualquer técnica transmitida, como qualquer conhecimento aportam, clandestinamente ou não, outros saberes. Tais contaminações nunca são inócuas e nem poderiam ser açodadamente consideradas nefastas ou positivas, o fato é que o exemplo aqui escolhido evidencia as tramas de uma cidade imaginal que se estende virtualmente e por meio das mais diversas imagens.

Suas ruas, praças e arquitetura, embora na virtualidade, dispõem de vigoroso apelo realizador de sua corporeidade. A cidade invocada nas imagens ao mesmo tempo em que é território virtual opera condições de governo tangíveis, como a exclusão, a segregação, a hierarquização e demais estratégias tradicionais de dominação. E o que aqui mais interessa é que tais operações se dão com o recurso direto das imagens visuais e das suas capacidades de sedução e atração, ou seja, suas potências estéticas, suas irrecusáveis ofertas de algum oportuno gozo para além das significações que carregam.

Gozo, muitas vezes, em doses parceladas, programadas e gerenciadas segundo a economia do prazer aplicada pelas formidáveis e trágicas operações do mercado. Mercado tão abstrato quanto concreto, tão contrastante quanto a cidade virtual e a cidade tangível que o inventa e nela é gestado.

$\mathrm{Na}$ perspectiva da cultura visual não é possível tratar da imagem escapando de enfrentamentos severos via a demonização da força e da intensidade das imagens nem da cidade ou do mercado. É Indiscutível a gravidade de muitas das conseqüências da vida balcanizada e enclausurada na superfície sedutora das imagens produzidas em benefício desse sistema e que assediam o cotidiano de quase toda a humanidade.

Certamente que a quantidade de problemas decorrentes do poder do mercado leva à condenação e redução precipitada do universo das imagens e de seus constantes usos nas mídias. Entretanto, o desafio da imagem exige cautela e persistência na aventura de elucidação dos ônus e dos benefícios aos quais a imagem é associada.

Apontada como instrumento de sedução do olhar, a imagem remete ao corpo e ao embate entre sua totalidade sensorial e a sua redução à percepção dominante da visão. Corpo e imagem se encontram não apenas nessa discussão' mas, também, e principalmente, no âmbito do desejo estimulado pelo que é visível, assim como, nas exploradas e reivindicadas possibilidades do corpo como meio e suporte de imagens, como produto e produtor de visualidades. O corpo, então presa da sedução da imagem, também seduz quanto imagem ou imaginação. A força do desejo indiscernível do corpo, corpo máquina desejante, também opera ações outras que a mera subserviência ao 
desejo imposto. Somos, como propõem Deleuze e Guattari (2010) ao definir o ser humano no "O Anti-Édipo", máquinas desejantes. Não no sentido metafórico, mas, literalmente. Aludem os pensadores a máquinas acopladas a outras máquinas, máquinas produzindo conexões. Assim, tudo em nós cria, faz, corta, processa, produz... Nosso corpo é uma usina (idem). Inclusive de imagens, visuais, olfativas, táteis, sonoras, etc.

Diante da vigorosa participação da imagem visual nas mais diversas instâncias da vida cotidiana, seria difícil negar a específica predominância da visão nas mediações sociais. Inegável é, então, a participação ostensiva da visão frente aos outros sentidos, muito embora não se possa aceitar que a apreensão do que nos seria externo seja feita apenas por esse sentido, problema que provocou críticas dos que viam o olhar fragilizado em suas funções precípuas pelo excessivo confronto com a volumosa visualidade dos tempos recentes. O olhar despotencializado como símbolo das sociedades contemporâneas.

Sociedades cada vez mais plurais e complexas, em cuja tessitura predomina o franco intercâmbio do espetacular, processos de tensão e disputa nos quais o olhar, ser visto e fazer ver parecem aposentar ou colocar em quarentena quaisquer outros meios de intercâmbio, captação ou criação do real. A constatação da incompetência do olhar se confundiu com a condenação da imagem visual, responsabilizando a superfície visual do mundo pelos processos danosos que lhes seriam subterrâneos. Imagem e olhar se confundem como corpo e prótese não mais dissociáveis.

A palavra imagem, diretamente ligada ao que pode ser captado pela visão, logo evidenciaria não estar restrita à apresentação ou condição visual, pois, a despeito de sua afirmada hegemonia, outras formas de criação e percepção imagética, imagens sonoras, do pensamento, literárias, etc. estiveram e estão ativadas permanentemente em cumplicidade com a imaginação. E a sua produção visual evidencia relação muito mais complexa do que a mera hierarquia dos sentidos. Sendo a plataforma inicial das primeiras realizações humanas, o corpo humano enquanto instrumento de produção e também o aparelho de recepção do que Ihe é exterior, imbrica e complexifica os territórios externos e internos a si próprio. A exterioridade e a interioridade seriam apenas territorialidades tão imagéticas quanto as palavras que invocam sensações visuais, sonoras, palatais, olfativas, etc.

O corpo é, certamente, o instrumento produtor de todo artefato visual feito pelo homem sendo, também ele, o local onde se produzem todas as imagens provenientes do mundo que Ihe cerca. O "mecanismo do olhar", que seria o sentido da visão, não seria, contudo, redutível às operações fisiológicas do conjunto óptico do corpo humano. Uma paisagem 
captada em pleno funcionamento dessa mecânica seria vazia de forma e sentido se não dispusesse do acúmulo de outras experiências em acervos permanentemente reconfigurados sob a ação das colisões, amálgamas e demais consequências do assentamento das sucessivas e diversas experiências sobre o corpo memória e criação.

Interrompendo a apresentação de alguns entendimentos maiores sobre a imagem visual que é um dos interesses da nossa rede investigativa, sublinhamos a relevância da cultura visual como rede de formas e maneiras de lidar e produzir imagens visuais que açambarcam não apenas aquelas que são oriundas do sistema de arte, produtos da arte outorgada como o conjunto de coisas produzidas por técnicas diferenciadas, mas tendo, entre si, afinidades pelas quais se constituem em sistema. Conjunto importante na medida em que circunscreveu e por vezes mediou a experiência da realidade de forma quase hegemônica no Ocidente até o advento da Modernidade (ARGAN, 1992, pp. 508 a $512)$.

Para além deste sistema, a cultura visual abrange toda a ampla produção oriunda dos avanços tecnológicos conquistados no decorrer e contexto das revoluções industriais, como a fotografia e o cinema e todas outras formas de conceber a imagens e instituir seus papéis sociais. Com atual destaque à posterior revolução cibernética que fez a imagem digital nascer e se proliferar incontrolavelmente. Fazem parte da visualidade também toda a produção relativa ao que se convencionou chamar de artes menores, artes aplicadas etc. não sendo excluídas as oriundas da nomeada arte popular, do folclore, da arte da rua, ou urbana. Em síntese, toda a produção humana relativa às manifestações estéticas produzidas meio às diversas culturas que compõem a humanidade no inextrincável jogo corpo e imagem.

\section{A diferença: há diferença}

Outro norte, ou referência central, nas pesquisas desenvolvidas na linha é a noção da diferença como base das projeções das investigações em curso. Diluindo a equivocada escapatória da identidade, a diferença se impõe como conceito chave para as investigações que se situam na convergência da arte, da formação humana e dos modos estéticos de ser e estar no mundo.

Entendendo que a diferença está posta na criação dos sistemas simbólicos, nos quais os signos nunca correspondem aos seus significados em plena fidelidade e que a igualdade como determinação política soçobra sobre os escombros dos marcos territoriais do mesmo e do outro. 
É importante compreender que a identidade, em permanente jogo de oposição ou polaridade com a diferença, nada mais é que trânsito e, muitas vezes, abrigo indispensável meio aos desafios sociais provocado pelos aplainamentos culturais, pasteurizações existenciais e demais operações de fragilização dos coletivos. Assim, a diferença é o que há e se assenta na indestrutível constatação de que o outro pode ser o que somos assim como pode ser o que não somos com tanta plenitude e eloquência quanto intima, permanentemente, que desejemos ser alguma coisa. Alguma coisa radicalmente diversa da afirmação das identidades autorizadas e sempre reduzidas a uma afirmação tão drástica quanto vazia na positividade daquilo que se permite ser.

A diferença destacada na acepção da desconstrução não é o postulado da destruição. Longe de ser destruído, o signo em discussão, seja qual for, gênero, beleza ou verdade, será, sob nova abordagem, tomado como prioritário ao referente, e o significante como prioritário ao significado, de forma que não existirá mais a coisa em si, genérica, perturbadoramente universal e fora das redes de remissões dos signos.

Quanto à linguagem que blinda e enclausura sentidos e vocabulários, porquanto as suas diferentes formas de expressão, esta já poderia ser considerada um impedimento ou conceituação de uma possível realidade. Seriam as considerações encadeadas a essas colocações a argumentação sobre a importância da 'diferença' em nossas pesquisas.

Colocações aproveitadas da obra de Jacques Derrida, para o qual a palavra diferença será entendida quando nos vemos levados a constatar quando começamos a dar nome e sentido às coisas existentes, ação, de certo modo que se dá como produção filosófica.

Nas experiências subjetivas que implicam na linguagem, a potência do sentido da 'diferença' se coloca ao percebermos as distâncias entre o que escrevemos e o que falamos, os signos que utilizamos e os elementos aos quais eles se referem.

O que seria exatamente a diferença em seu sentido maior? A diferença é, além de outras definições, a desconstrução de toda ordem de limites que acomodam as relações com o mundo no conforto de uma idealizada igualdade universal. É, portanto o imprevisível, o inusitado e, assim, incontrolável. Deleuze afirma, de forma contundente, que a razão clássica não pode apreendê-la sem, com isso, destruir a sua natureza "rebelde e anárquica".

Definir a diferença seria colonizá-la pela estabilização conceitual, seria reduzir seu universo de possíveis em um nicho conceitual. Na história da filosofia, a diferença, de 
certo modo, foi mantida no antagonismo dos conceitos familiares. Aludida como algo inalcançável para além do aventável, seria também a insuportável dessemelhança. Apartada do que somos, estaria relegada ao abominável irreal, ao monstruoso, cuja função se reduziria a reforçar que é o que não somos. Ou ratificar que não somos o que se convencional abominar. Invadindo o pensamento, ou se presentificando nos sentidos, tomando a nossa percepção a diferença é imediatamente denunciada como o que subverte e põe em risco o que é, ou o que tem a hegemonia da legalidade. Entretanto, a diferença é o principio constitutivo da natureza, tomando-a como a trama de realidades que nos cercam, penetram e nos constituem. Contudo, a ideia, e mesmo o conceito de diferença, remete ao não dito, ao indizível, ao maldito. Aquilo que ameaça ampliar os territórios controlados e aportar o mal da incompreensão, da surpresa, do indômito, do não apreendido, do que não se pode sorver ou saborear nas condições e meios familiares, nas palavras conhecidas, na língua praticada.

\section{Os cotidianos escolares e urbanos e suas práticas poéticas}

A partir de Certeau (idem) é constatável que nada há além do cotidiano. Embora seja no espaço e tempo cotidiano, meio às rotinas e suas repetições, que fulgurem as narrativas que sugiram esferas além, superiores em forma e potência da ordinariedade que se vive.

Ordinariedade palpável e quando percebida com atenção, o que realmente não oferece é a repetição. Assim como os coletivos, e nesses os indivíduos são singulares, as suas práticas diárias refletem comparável singularidade. Assim, as cidades e suas instituições possuem, no mínimo, duas realidades diversas. A da narrativa institucionalizante que as afirmam ou enunciam em sentido universal - A cidade é; a escola é - e a realidade dos seus cotidianos que se configuram e se esvaem nos atos mínimos de seus praticantes, seus gestos, suas falas, seus encontros, suas imagens. Aspecto, este último, específico em virtude de seus potenciais estéticos e poéticos que atraem o interesse dos estudos das relações entre a arte na educação e a formação humana. Âmbito, por sua vez, permeado por todo tipo de assédio imagético, sejam as imagens incorporadas pelo currículo formal, sejam as que compõem os turbilhões visuais dos dispositivos de criação e circulação de imagens, as produções, autoproduções individuais e coletivas e toda sorte de encontro com as visualidades entendidas como criação e interlocução com as imagens visuais.

A instituição escolar representa um interminável arquipélago de realidades distintas e variáveis e, nesse sentido, reflete outro universo cuja denominação pouco sugere de sua multiplicidade, complexidade e condição polimórfica, a 'cidade'. 
O termo cidade, conceito universalizado, designa planos extensos de intensa ocupação visual, nos quais se destacam muitas imagens sobre a invisibilidade de inumeráveis outras visualidades. Visualidades negadas, ou interditadas, cujos pontos de aproximação são a ilegitimidade, a marginalidade, a ilegalidade ou outra condição determinada pelos regimes de verdades legalizadas pela cidade hegemônica. Contudo, tais condições e o controle da cidade vigilante sobre elas não as impedem de florescer e de constituir cidades 'semi-visíveis' imiscuídas na visibilidade autorizada. E esse conjunto esquerdo constitui inegável contribuição ao universo de possíveis. Horizonte entendido como o vislumbre que cada olhar, partindo de suas plataformas teóricas e metodológicas, pode alcançar.

Na ordem prática, aludimos às imagens materializadas nas superfícies do corpo urbano, das melhores contempladas pela ampla visibilidade às reentrâncias mais ocultas, secundarizadas nas bordas ou periferias, como exemplo mais imediato, a pichação de inegável teor político e estético.

Referimo-nos também às imagens que se movimentam nos corpos, nas improvisações, nas oportunidades fugidias dos comércios ambulantes ilegais, nas performances das populações de rua, nas músicas que tomam de assalto a paisagem sonora da cidade de desdobramentos incontroláveis. Torrente imagética que forma e conforma ideias sobre os coletivos, os indivíduos, seus abrigos comunitários, seus espaços relacionais e, o mais crucial, seus limites e interditos de ação. A cidade, ou as cidades negadas que habitam a cidade lícita educam tanto quanto a ordenação hierarquizadora dessa última. O eloqüente embate entre as cidades em tensão oferece, então, um manancial de proposições imagéticas, estéticas e poéticas à exploração pedagógica tanto para a Arte quanto para a Formação humana assumindo o desfronteiramento curricular e a virtualidade dos limites entre escola, ateliê e cidade.

A escola e suas produções, seja a escola do ensino formal obrigatório, seja a configurada nas ofertas diversificadas de ensino de alguma linguagem artística, confrontada com as cidades que habitam, proporcionam problematizações indispensáveis à atualização do conhecimento sobre o ensino da arte e seus sentidos atuais.

A específica participação das Artes na formação escolar solicita ser compreendida meio ao enfrentamento dos desafios que a instituição escolar enfrenta. Uma instituição cada vez menos independente e autônoma em relação às demais instituições oficializadas, ou não, no panorama complexo das cidades. Refletir sobre a instituição escolar, seja no plano conceitual ou na referência singular de seus cotidianos, implica em não dissociá-la 
da dinâmica das culturas que compõem o magma social e seus cenários urbanos.

Nossas pesquisas, direcionadas às produções imagéticas dos jovens nas escolas, tomam esse manancial de narrativas visuais para além da planura de seus suportes e não evitam o desconforto e perplexidade gerados a cada movimento investigativo, assim como buscam evitar a embriaguez dispersiva decorrente do maravilhamento diante das belezas encontradas. Certamente que o caminho equilibrado meio a um campo tão sedutor é praticamente impossível ser mantido durante todo o percurso das pesquisas, sobretudo quando os pesquisadores guardam assumida cumplicidade e pertencimento ao campo investigado. O que, certamente, intensifica o grau de desafios das tarefas, mesmo que assumidamente sejam pesquisas com intenso grau de poeticidade. Condição que não as afastam do exigido compromisso acadêmico e/ou poético.

A Literatura, o Teatro, o Cinema e demais meios de expressão poética avançam, como só a arte a princípio o faz, sobre o campo do improvável, do contraditório, do paradoxal e, nessas realizações, intercambiam, se contaminam e atravessam as aventuras sociais que realizam as novas gerações os espaços que praticam cotidianamente. A linguagem da Performance, a Arte Urbana, as produções que emergem das propostas da Estética Relacional, a Arte Colaborativa (BOURRIAUD, 2009) são exemplos de norteamentos de produções e princípios poéticos que, contando com as tessituras sociais envolvidas, os oikos, ou cenários existenciais, apontam campos a serem explorados pelas pesquisas que conjugam os interesses pelas estéticas da existência, pelo alargamento das fronteiras das benesses sociais, pelas políticas da afirmação das diferenças, e demais objetivos de uma sociedade justa.

Propor a utilização de concepções artísticas para conduzir práticas diversas à arte, ou seja, de uma forma particular de pesquisar e produzir conhecimento, qual seja a expressão artística, pode parecer à leitura açodada, um disparate ou de pouca serventia, entretanto, a defesa da ação investigativa que se apoia, entre outros princípios, na literaturização da ciência (ALVES; OLIVEIRA, 2008) e o reconhecimento da ação poética da performance nas ordinárias ações docentes (PEREIRA, 2012) já são defendidas e conhecidas há algum tempo.

Interrompo, aqui, as considerações a respeito das bases conceituais que norteiam as pesquisas sob a minha orientação no Programa de Pós-graduação em artes da UERJ e que de certa forma, a contrapelo das pesquisas voltadas para o campo oficial da Arte, investe nas ações estéticas nas quais os termos arte, artista, autoria, obra de arte e demais signos do campo ou sistema das Artes, não sobrepujam a vida ordinária, as inusitadas ações e interferências nos corpos das gentes e das cidades. São esses últimos, 
cidadãos anônimos, corpos estetizados, malditos embelezados e tantas outras formas de seres e estares no mundo que interessam à percepção das pesquisas que farejam indícios de vidas outras, outras belezas, outros mundos e maneiras de viver possíveis no mundo de hoje.

Já antes, no sentido de enriquecer o universo humano das relações sociais, do conforto existencial, da rede das solidariedades e os acolhimentos, forjam a escultura que interessa aos tempos de então. A obra de arte, irredutível aos interesses mercantis e que se atém às produções poéticas que constituem a afirmação da possível igualdade solidária da humanidade como realização estética, se alia ao postulado básico da estética relacional (BOURRIAUD, 2009) que seria a esfera das relações humanas como obra de arte, obras que se dão meio aos modos de intercâmbios sociais, ou seja, na interação do individuo com o coletivo no âmago da experiência estética proposta.

\section{Referências}

ARGAN, Giulio. Arte Moderna: do Iluminismo aos Movimentos Contemporâneos. São Paulo: Companhia das Letras, 1992.

ALVES, Nilda Guimarães; OLIVEIRA, Inês B. de (Orgs.). Pesquisa nos/dos/com os cotidianos das escolas. 3. ed. Petrópolis: DP et Alii, 2008.

BOURRIAUD, Nicolas. Estética relacional. São Paulo: Martins, 2009.

CERTEAU, Michel de. A Invenção do cotidiano 1. Petrópolis: Editora Vozes, 1994.

DELEUZE, Gillles; GUATTARI, Felix. O anti-Édipo: Capitalismo e esquizofrenia . São Paulo: Editora 34, 2010.

DERRIDA, Jacques. Margens da Filosofia. Campinas: Papirus, 1991.

FLUSSER, Vilém. Filosofia da caixa preta: ensaios para uma futura filosofia da fotografia. Rio de Janeiro: Relume Dumará, 2007.

GIL, José. Metamorfoses do corpo. Lisboa: Relógio D’Água Editores, 1997.

SILVA, Sara Rosa Panamby da. Corpolimite: estados insistentes de desterritorialização das matérias. Anais ANPAP, 2013.

http://www.anpap.org.br/anais/2013/ANAIS/simposios/03/Sara\%20Panamby.pdf Revista Digital do LAV - Santa Maria - vol. 8, n.4, p. 03-17 - Jan./Abr.2015 ISSN 1983-7348 
PEREIRA, Marcelo de Andrade, et al. Pedagogia da performance: da Presença, do humor e do riso na Prática pedagógica. Revista Contrapontos - Eletrônica, Vol. 12 - n. 3 - p. 335-340 / set-dez 2012.

\footnotetext{
' Professor adjunto do Instituto de Artes da UERJ; docente dos programas de pósgraduação em Educação - PROPED e Artes - PPGARTES; líder do Grupo de Pesquisa Estudos Culturais em Educação e Arte (UERJ e UFRRJ), coordenador do Laboratório de Ensino da Arte(UERJ), pesquisador dos Grupos de Pesquisa Cotidiano Escolar e Currículo - UERJ, Linhas de Pesquisa: Práticas curriculares cotidianas e emancipação social e Cultura Visual e Educação - UFG. E.mail: vitorio aldo avictorio@gmail.com
}

Recebido em: 14 de novembro de 2014.

Aprovado em: 10 de abril de 2015. 